\title{
LEVELS OF MAJOR AND TRACE METALS IN THE LEAVES AND INFUSIONS OF CROTON MACROSTACHYUS
}

\author{
Amare Aregahegn Dubale ${ }^{1}$, Bhagwan Singh Chandravanshi ${ }^{1 *}$ and Kidane Fanta Gebremariam ${ }^{2}$ \\ ${ }^{1}$ Department of Chemistry, Faculty of Science, Addis Ababa University, P.O. Box 1176, Addis \\ Ababa, Ethiopia \\ ${ }^{2}$ Department of Chemistry, Norwegian University of Science and Technology, 7491 Trondheim, \\ Norway
}

(Received May 11, 2014; revised October 10, 2014)

\begin{abstract}
The levels of essential metals (Ca, $\mathrm{Mg}, \mathrm{Fe}, \mathrm{Mn}, \mathrm{Zn}, \mathrm{Cu}, \mathrm{Co}, \mathrm{Cr}, \mathrm{Ni})$ and toxic metals $(\mathrm{Cd}, \mathrm{Pb})$ were determined in the leaves of Croton macrostachyus (traditional medicinal plant) collected from four different regions of Ethiopia (Akaki, Abomsa, Bonga and Dilla) and also in the infusions of leaves collected from Akaki using flame atomic absorption spectrometry. An optimized digestion procedure took $2.5 \mathrm{~h}$ for the digestion of 0.5 g of powdered sample with $2 \mathrm{~mL}$ of $\mathrm{HNO}_{3}$ and $2 \mathrm{~mL}$ of $\mathrm{HClO}_{4}$ at $270{ }^{\circ} \mathrm{C}$ while $2 \mathrm{~h}$ were needed to digest $25 \mathrm{~mL}$ infusion with $4 \mathrm{~mL}$ of $\mathrm{HNO}_{3}$ and $1 \mathrm{~mL} \mathrm{HClO}_{4}$. The recoveries of metals were in the range $92-103 \%$ for the leaves powder and $94-105 \%$ for the infusion samples. The mean concentration ranges $(\mu \mathrm{g} / \mathrm{g})$ were $\mathrm{Ca}(5,823-12,040)$, $\mathrm{Mg}(1,971-4,961), \mathrm{Fe}$ (192-581), Mn (157-1,770), Zn (19.5-60.5), Cu (6.31-18.6), Co (1.97-3.45), Cr (2.138.75), $\mathrm{Ni}(2.15-3.80), \mathrm{Cd}(0.75-1.08)$ and $\mathrm{Pb}(1.05-2.19)$ for the leave powders and $\mathrm{Ca}(716-1,776), \mathrm{Mg}(16.7-$ 80.9), Fe (1.39-3.34), Mn (2.17-3.40), Zn (0.674-7.88), Cu (1.94-2.31), Co (0.157-0.224), Cr (0.144-1.23), Ni $(0.203-0.267), \mathrm{Cd}(0.05-0.098)$ and $\mathrm{Pb}(0.0148-0.185)$ for the infusion samples. Among the quantified metals in the infusion samples, Ca showed the highest leaching rate $(61.5 \%)$ in the $24 \mathrm{~h}$ infusion while Fe exhibit the lowest $(1 \%)$ leaching rate in the $3 \mathrm{~h}$ infusion.
\end{abstract}

KEY WORDS: Traditional medicinal plant, Croton macrostachyus, Croton leaves powder, Croton leaves infusion, Major metals, Trace metals, Ethiopia

\section{INTRODUCTION}

The use of plants as treatment of diseases and as food dates beyond recorded history perhaps as old as the history of mankind. Old civilisations in China, India, Egypt and Greece had a rich knowledge and expertise in using many types of plants. It has been estimated that more than $80 \%$ of the world population utilizes plants as primary source of medicinal agents, largely due to the high cost of Western pharmaceuticals, but also because the traditional medicines are generally more acceptable from a cultural and spiritual perspective. Even in the Western world, the use of herbal medicines is steadily growing with approximately $40 \%$ of the population reporting use of herbs to treat medical illness $[1,2]$.

It is known that many countries in Africa, Asia and Latin America use traditional medicine to meet some of their primary health care needs. In Africa, up to $80 \%$ of the population uses traditional medicine for primary health care. Traditional medicine has maintained its popularity in all regions of the developing world and its use is rapidly spreading in the industrialized countries. In China, for example, traditional herbal preparations account for $30-50 \%$ of the total medicinal consumption. In Ghana, Mali, Nigeria and Zambia, the first line of treatment for $60 \%$ of children with high fever resulting from malaria is the use of herbal medicines at home [3].

Many of the plants species used for this purpose have been found to contain therapeutic substances which can be extracted and used in preparation of drugs, but the plant itself can also be used either directly or as an extract for medication, a practice that is particularly popular in developing countries [4-7].

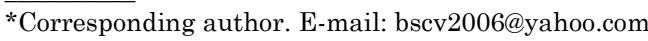


Ethiopia has a long history of traditional medicine and has developed ways to combat disease through it. The ways are also as diverse as the different cultures, language and belief. In Ethiopia up to $80 \%$ of the population uses traditional medicine due to the cultural acceptability of healers and local pharmacopeias, the relatively low cost of traditional medicine and difficult access to modern health facilities [3].

In Ethiopia, traditional remedies represent not only part of the struggle of the people to fulfil their essential drug needs but also they are integral components of the cultural beliefs and attitudes [8]. Some of the common uses of the medicinal plants sold in markets include fumigation, vermifuge, pain relief and treating skin infections. Antimicrobial and wound healing plants are among some of the major medicinal plants that are commonly available in markets $[6$, $7,9]$. Despite its significant contribution to society, traditional medicine has received very little attention in modern research and development and less effort has been exerted to upgrade the traditional health practices in the country. But, the long history of use of medicinal plants in Ethiopia and its huge biotic riches can be of paramount importance in future research and drug discovery [10]. Even today, this huge traditional knowledge of medicinal plants is playing an important role in the development of new drugs. An example of drugs discovered based on information derived from an ethnobotanical investigation is aspirin from Filipendula ulmar, morphine from Papaver sominferum, ephedrin from Ephedra sinica to name a few [11].

Of the many medicinal plants in Ethiopia, Croton macrostachyus is the most common. Croton macrostachyus Hochst. ex Del. is commonly known as rush foil or broad-leaved Croton (English), Bisana (Amharic and Shinasha), Makanissa, Bakkanissa, Badessa, Alaleh, Dogoma (Oromo), Wusha, Masincho (Sidama), and Islami, Tambuk and Tambush (Tigrigna). It belongs to the Euphorbiaceae, a very large family with 300 genera and 8,000 to 10,000 species, and is the most abundant plant in the tropics [12-15].

It is native to Eritrea, Ethiopia, Kenya, Tanzania, Uganda and Nigeria. It is a medium sized deciduous tree of East Africa particularly wide spread between 200-2500 masl in mountainous forests and savannah of the tropical regions and ever green bush land areas that receive between $700-2000 \mathrm{~mm}$ rainfalls annually [16]. It is $3-25 \mathrm{~m}$ high, although more commonly $6-12 \mathrm{~m}$. In Ethiopia, C. macrostachyus grows between 500 and 3400 masl (more frequently between 1100 and 2700 masl) $[17,18]$.

As C. macrostachyus is available almost in all parts of Ethiopia, people are using it as a medicine for treatment of snakebite, malaria, headache, internal worms, rabies, gonorrhea, ascarasis, sexually transmitted diseases and tinea versicolor for human being in which the traditional medician ordered the patients to take unlimited dosage of the plants part like to take two, three or even more glasses of medicinal plant extract orally. The plant is also used for fever and wounds of domestic animals [18]. The leaves of C. macrostachyus have medicinal value including cold leaf decoction is drunk or ashes taken orally as treatment for cough; juice from fresh leaves is applied on wounds to hasten clotting.

Plants constitute is an important link to the transfer of trace elements from soil to man. The level of elements in plants varies, the content being affected by the geochemical characteristics of a soil and by the ability of plants to selectively accumulate some of these elements. Bioavailability of the elements depends on the nature of their association with the constituents of a soil. Additional sources of these elements for plants are rainfall, atmospheric dusts, plant protection agents and fertilizers that can be absorbed through the leaf blades [19-26].

Trace elements have both a curative and a preventive role in combating diseases. It is therefore of major interest to establish the levels of some metallic elements in common herbal plant because, at elevated levels, these metals can also be dangerous and toxic [27, 28]. Though they are required in very small amount, deficiency of trace elements causes diseases, whereas their presence in excess may result in toxicity to human life disturbing normal functioning of organs and central nervous system $[29,30]$. 
The literature survey revealed that there is no report on the levels of metals in leaves of $C$. macrostachyus. Thus the objectives of this study were: (i) to determine major and trace essential $(\mathrm{Ca}, \mathrm{Mg}, \mathrm{Fe}, \mathrm{Mn}, \mathrm{Zn}, \mathrm{Cu}, \mathrm{Co}, \mathrm{Ni}, \mathrm{Cr}$ ) and toxic metals $(\mathrm{Cd}, \mathrm{Pb})$ in leaves of $\mathrm{C}$. macrostachyus and its infusion grown in Ethiopia by flame atomic absorption spectroscopy, (ii) to compare the levels of essential (Ca, Mg, Fe, Mn, $\mathrm{Zn}, \mathrm{Cu}, \mathrm{Co}, \mathrm{Ni}, \mathrm{Cr})$ and toxic $(\mathrm{Cd}, \mathrm{Pb})$ metals in the leaves and infusions of C. macrostachyus, (iii) to estimate the amount of elements released from plants into the water extracts, and (iv) to look some correlation trends among the element concentrations in the different area of study by applying simple statistical tools.

\section{Apparatus and instrument}

\section{EXPERIMENTAL}

Teflon (PTFE, China) knives were used to cut the C. macrostachyus leaves in to pieces and an oven (Digitheat, J.P. Selecta, Spain) was used for drying the samples placed on porcelain dish. Blending device (Moulex, France) and ceramic pestle and mortar were used for grinding and homogenizing the C. macrostachyus leaves samples. C. macrostachyus samples were digested on Kjeldahl heating apparatus (Gallenkamp, England) using round bottom flasks with ground glass joint $(100 \mathrm{~mL})$ fitted with reflux condenser. Borosilicate volumetric flasks $(25,50$ and 100 $\mathrm{mL}$ ), pipettes (Pyrex, USA), measuring cylinders (Duran, Germany), and micropipettes (Dragonmed, 1-10 $\mu \mathrm{L}, 100-1000 \mu \mathrm{L}$, Shanghai, China) were used for measuring different quantities of sample solution, acid reagents and metal standard solutions. Metal concentrations were determined by flame atomic absorption spectrophotometer (Buck Scientific, Model 210VGP AAS, East Norwalk, USA) equipped with deuterium background corrector and hollow cathode lamps with air-acetylene flame.

Chemicals and reagents

All the reagents were of analytical grade. $69-70 \% \mathrm{HNO}_{3}$ (Supreme Enterprises Cantt, India) and $70 \% \mathrm{HClO}_{4}$ (Aldrich, UK) were used for the digestion of the C. macrostachyus leaves and infusion samples. Lanthanum nitrate hydrate, $(99.9 \%$, Aldrich, USA) was used to prevent the chemical interference on $\mathrm{Ca}$ and $\mathrm{Mg}$ in the sample solution during the analysis of $C$. macrostachyus samples. Stock standard solution of concentration $1000 \mathrm{mg} / \mathrm{L}$ in $2 \% \mathrm{HNO}_{3}$ of the metals $\mathrm{Ca}, \mathrm{Mg}, \mathrm{Mn}, \mathrm{Fe}, \mathrm{Zn}, \mathrm{Cu}, \mathrm{Zn}, \mathrm{Cr}, \mathrm{Ni}, \mathrm{Co}, \mathrm{Cd}$ and $\mathrm{Pb}$ (Buck Scientific Puro-Graphic ${ }^{\mathrm{tm}}$ ) from which $10 \mathrm{mg} / \mathrm{L}$ of intermediate standard obtained were used for the preparation of the calibration standards of each metal. Working standards were prepared from intermediate standards of each metal. Deionized water was used for sample preparation, dilution, and rinsing apparatus prior to analysis.

\section{Description of the study area}

The samples were collected from the selected sites of four different regions namely: (i) Abomsa, a town in central Ethiopia - located in the Arsi Zone of the Oromia region, administrative center of Merti Woreda, (ii) Dilla, a market town in southern Ethiopia - the administrative center of the Gedeo Zone in the Southern Nations, Nationalities and People Region (SNNPR), and located on the main road from Addis Ababa to Nairobi, (iii) Akaki, one of the outskirt sub-cities of Addis Ababa and (iv) Bonga, the administrative center of Kefa zone in the Southern Nations, Nationalities and People Regional state. The selection of these sites was based on: firstly, availability of ethnobotanical information, secondly, the need to compare metal accumulation in this plant from industrially and agriculturally polluted areas with that of none polluted environment; thirdly, availability of the plant and its popularity in using as medicinal plant by the local peoples around. The geographical location of the sampling sites and their distance from Addis Ababa (capital city of Ethiopia) are given in Table 1. 
Table 1. The geographical location of the sampling sites and their distance from Addis Ababa (capital city of Ethiopia).

\begin{tabular}{|l|l|l|l|l|}
\hline Sampling site & Latitude & Longitude & Altitude $(\mathrm{m})$ & Distance $(\mathrm{km})$ \\
\hline Abomsa & $8^{\circ} 35^{\prime} \mathrm{N}$ & $39^{\circ} 51^{\prime} \mathrm{E}$ & 1438 & 202 \\
\hline Dilla & $6^{\circ} 24^{\prime} 30^{\prime} \mathrm{N}$ & $38^{\circ} 18^{\prime} 30^{\prime \prime} \mathrm{E}$ & 1570 & 359 \\
\hline Akaki & $9^{\circ} \mathrm{N}$ & $38^{\circ} 45^{\prime} \mathrm{E}$ & $2200-2800$ & 23 \\
\hline Bonga & $6^{\circ} 15^{\prime}$ to $8^{\circ} 08^{\prime} \mathrm{N}$ & $35^{\circ} 30^{\prime}$ to $36^{\circ} 46^{\prime} \mathrm{N}$ & $500-3350$ & 440 \\
\hline
\end{tabular}

Sample collection and treatment

Representative amount of leaves were collected from four different regions. The leaves were collected from a minimum of 16 mature plants, four plants per region and eight leaves per plant starting from the bottom to the tips by stalk position. The C. macrostachyus samples were put in clean plastic bags labeled according to their region and brought to the laboratory for further pretreatment. The leaves of the C. macrostachyus were separated with Teflon knives, washed with a running tap water so as to remove adsorbed soil particulates and then rinsed with distilled deionized water and air dried. About $300 \mathrm{~g}$ of the C. macrostachyus leaves from each region were put on acid-washed and labeled porcelain dish and dried in an oven at $80{ }^{\circ} \mathrm{C}$ for $48 \mathrm{~h}$ till it got brittle and crisp. After cooling to ambient temperature, the dried samples were ground in to fine powder with blending device, mortar and pestle, and sieved $(1 \mathrm{~mm})$. The powdered sample was then placed in pre-cleaned screw capped polyethylene container and stored in desiccators with calcium chloride to keep to constant dry weight till digestion.

The C. macrostachyus leaves infusion was made from C. macrostachyus leaves collected from Akaki site only. By varying the time, four C. macrostachyus leaves infusion samples were prepared. As there is no specific method of preparing the C. macrostachyus leaves infusion in Ethiopia, usually $25 \mathrm{~g}$ of fresh leaves ( 8 to 14 leaves) were ground in the mortar with a pestle and were added in to a $250 \mathrm{~mL}$ tap water (at room temperature, $25{ }^{\circ} \mathrm{C}$ ). This was done on the habits of traditional medician, i.e. they keep the leaves in the water for half a day or for complete day depending on the ages of the patient. So, in this study, to compare and consider the amount of metals extracted in to the supernatant, the infusions were prepared for 3, 6, 12 and 24 hours. Finally, pure infusion sample was obtained by filtering and the decrease in volume was compensated by adding water up to the mark.

\section{Optimization of digestion procedure}

Before applying the digestion procedure for the analysis of samples, digestion time, reagent volume ratio and temperature were optimized by varying one parameter at a time for the digestion of $C$. macrostachyus leaves powder and its infusion. Thus, for a complete digestion of

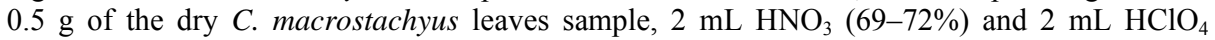
$(70 \%)$ for a total of $2.5 \mathrm{~h}$ at $270{ }^{\circ} \mathrm{C}$ was selected as optimized procedure while $1 \mathrm{~mL} \mathrm{HClO}_{4}$ $(70 \%)$ and $4 \mathrm{~mL}$ of $\mathrm{HNO}_{3}(69-72 \%)$ for a total of $2 \mathrm{~h}$ at $240{ }^{\circ} \mathrm{C}$ for the digestion of $\mathrm{C}$. macrostachyus leaves infusion samples.

\section{Digestion of the C. macrostachyus leaves and its infusion}

Applying the optimized procedure, exactly $0.5 \mathrm{~g}$ of the dried and ground C. macrostachyus leaves sample was accurately weighed and transferred quantitatively in to a $100 \mathrm{~mL}$ round bottom digestion flask. To the C. macrostachyus leaves sample, $4 \mathrm{~mL}$ of freshly prepared 1:1 mixture of $70 \%$ of conc. $\mathrm{HNO}_{3}$ and $70 \%$ of conc. $\mathrm{HClO}_{4}$ was added. The mixture was then heated on Kjeldahl heating apparatus fitting the flask to a reflux condenser for the first $30 \mathrm{~min}$ by setting the temperature at $120{ }^{\circ} \mathrm{C}$ and followed by heating at $270{ }^{\circ} \mathrm{C}$ as maximum temperature for the other $2.0 \mathrm{~h}$. 
The digested solutions were allowed to cool for $20 \mathrm{~min}$ without dismantling the condenser from the flask and for an additional 10 min after removing the condenser. To the cooled solution, two $5 \mathrm{~mL}$ of de-ionized water was added and the solution was slowly shacked to dissolve precipitates remained on the wall of the flask and to minimize dissolution of filter paper by residue. Subsequent rinsing the flask with $5 \mathrm{~mL}$ portions of distilled-deionized water followed until the volume reached the mark. For each bulk samples, triplicate digestions were carried out. The digested and diluted sample solutions were stored in tightly capped polyethylene bottles and kept in refrigerator until analysis time.

To determine the amount of metals extracted from the C. macrostachyus leaves to the leaves infusion (to the water at room temperature, $25^{\circ} \mathrm{C}$ ) $25 \mathrm{~mL}$ of the clear infusion (after filtration) was transferred quantitatively to the $100 \mathrm{~mL}$ round bottom flask and heated on the hot plate to evaporate until the sample was decreased to around $3 \mathrm{~mL}$. This was done to avoid dilution of the acid mixture added for digestion. The solution was allowed to cool before the addition of the acid mixture to avoid potentially explosive reactions that may occur. A $5 \mathrm{~mL}$ portion of 4:1 $\mathrm{HNO}_{3}$ and $\mathrm{HClO}_{4}$ was added and the contents swirled gently to homogenize then fitted to a reflux condenser and digested continuously for two hours on a Kjeldahl digestion block. The temperature was adjusted at $120{ }^{\circ} \mathrm{C}$ for the first $30 \mathrm{~min}$ and finally to the maximum temperature of $240{ }^{\circ} \mathrm{C}$ for $1.5 \mathrm{~h}$. The contents were diluted to $50 \mathrm{~mL}$ as described above. The digestion gave a clear colorless solution. Each C. macrostachyus leaves infusion sample was digested in triplicate and hence a total of twelve digests were made for $C$. macrostachyus leaves infusion samples prepared by infusing for 3, 6, 12, 24 hours. All the final digest solutions were kept in a refrigerator until the analysis for the metals.

Digestion of a reagent blank was also performed in parallel with the C. macrostachyus samples keeping all digestion parameters the same. For the analysis of the C. macrostachyus samples 9 reagent blank samples were prepared. All the digested samples were stored in refrigerator until analysis. The solutions were used to determine concentration of the 11 elements by flame atomic absorption spectrometry.

\section{Instrument calibration and method detection limit}

For the present study, the pooled standard deviation of the 9 reagent blanks was calculated. The detection limits were obtained by multiplying the pooled standard deviation of the reagent blank by three. The wavelengths at which analysis was done, the correlation coefficients of the calibration curve for each of the metals and method detection limits of each metal are given in Table 2 . The results clearly show that the calibration curves with good correlation coefficients and lower method detection limits were obtained during the analysis.

Table 2. Method detection limits for C. macrostachyus leaves, and leaves infusion samples.

\begin{tabular}{|c|c|c|c|c|}
\hline Metal & Wavelength (nm) & $\mathrm{r}^{2}$ & $\begin{array}{c}\text { MDL for the leaves } \\
\text { samples }(\mu \mathrm{g} / \mathrm{g})^{\mathrm{a}}\end{array}$ & $\begin{array}{l}\text { MDL for infusion } \\
\text { samples }(\mu \mathrm{g} / \mathrm{g})^{\mathrm{a}}\end{array}$ \\
\hline $\mathrm{Ca}$ & 422.7 & 0.99994 & 3.1 & 5.2 \\
\hline $\mathrm{Mg}$ & 285.2 & 0.99999 & 2.6 & 4.1 \\
\hline $\mathrm{Fe}$ & 248.3 & 0.99997 & 0.05 & 0.07 \\
\hline $\mathrm{Mn}$ & 279.5 & 0.99993 & 1.1 & 2.0 \\
\hline $\mathrm{Zn}$ & 324.8 & 0.99952 & 0.4 & 0.5 \\
\hline $\mathrm{Cu}$ & 213.9 & 0.99924 & 1.2 & 1.5 \\
\hline $\mathrm{Co}$ & 240.7 & 0.99953 & 0.1 & 0.13 \\
\hline $\mathrm{Cr}$ & 341.5 & 0.99999 & 0.11 & 0.12 \\
\hline $\mathrm{Ni}$ & 357.9 & 0.99933 & 0.08 & 0.20 \\
\hline $\mathrm{Cd}$ & 228.9 & 0.99981 & 0.30 & 0.40 \\
\hline $\mathrm{Pb}$ & 217.0 & 0.99999 & 0.11 & 0.13 \\
\hline
\end{tabular}

${ }^{\mathrm{a}} \mathrm{MDL}=$ method detection limit. 


\section{Precision}

The precision of the results of the present analysis is reported with corresponding pooled standard deviation of nine measurements for a bulk sample of triplicate reading per sample and relative standard deviation.

\section{Recovery test}

The efficiency of the optimized procedure was checked by adding known concentration of each metal to $0.5 \mathrm{~g}$ sample. The procedure was as follows: $783 \mu \mathrm{g}$ of $\mathrm{Ca}$ and $0.6 \mu \mathrm{g}$ of Co were spiked at once in to $0.5 \mathrm{~g}$ of $C$. macrostachyus leave powder sample and the remaining metals (58 $\mu \mathrm{g}$ of Fe, $28 \mu \mathrm{g}$ of Mn, $6 \mu \mathrm{g}$ of $\mathrm{Zn}, 5 \mu \mathrm{g}$ of Cu, $0.92 \mu \mathrm{g}$ of $\mathrm{Cr}, 0.54 \mu \mathrm{g}$ of $\mathrm{Cd}$ and $0.88 \mu \mathrm{g}$ of $\mathrm{Pb})$ were spiked at once in to another round bottomed flask containing $0.5 \mathrm{~g}$ of $C$. macrostachyus leave powder. Similarly, $496 \mu \mathrm{g}$ of $\mathrm{Mg}$ and $0.84 \mu \mathrm{g}$ Ni were spiked at once in a flask containing $0.5 \mathrm{~g}$ of $C$. macrostachyus leave powder sample.

Since the concentration of metal in the C. macrostachyus leaves infusion is lower than that of the C. macrostachyus leaves powder, the recovery test for the C. macrostachyus leaves infusion was done by adding smaller amount of the spiked metals than that of the $C$. macrostachyus leaves powder. Hence, for spiking C. macrostachyus leave infusion sample, 183 $\mu \mathrm{g}$ of $\mathrm{Ca}, 0.31 \mu \mathrm{g}$ of $\mathrm{Cu}, 0.24 \mu \mathrm{g}$ of $\mathrm{Co}$, and $0.73 \mu \mathrm{g}$ of $\mathrm{Cr}$ were spiked from stock solution of each metal per gram of the sample. The remaining metals $(8.50 \mu \mathrm{g}$ of $\mathrm{Mg}, 0.98 \mu \mathrm{g}$ of $\mathrm{Fe}, 0.34$ $\mu \mathrm{g}$ of $\mathrm{Mn}, 0.17 \mu \mathrm{g}$ of $\mathrm{Ni}, 0.11 \mu \mathrm{g}$ of $\mathrm{Cd}$ and $0.16 \mu \mathrm{g}$ of $\mathrm{Pb}$ ) were spiked at once in to per gram of the infusion sample and $2.85 \mu \mathrm{g}$ of $\mathrm{Zn}$ was spiked in another flask containing the same amount of infusion sample and the same digestion process was followed. Each sample was analyzed for their respective spiked metals by atomic absorption spectrophotometer. Each recovery test for both samples was performed in triplicates.

\section{Conversion factor determination}

To report results obtained on a dry weight basis in terms of fresh weight basis, a conversion factor was calculated by taking the weight of a known quantity of fresh C. macrostachyus leaves before and after drying to a constant weight. This procedure was repeated for all the analysed plant leaves from different areas. Thus 4.17 , the mean value was taken as a conversion factor because $4.17 \mathrm{~g}$ of the wet sample (on an average) gave $1 \mathrm{~g}$ of dry sample.

\section{RESULTS AND DISCUSSION}

In this study, the method was validated by the spiking experiment in which known quantities of the metals standard solution were added to three samples for leaves and infusion samples. The spiked samples were then digested using the optimized procedure and calculated the percent recoveries. The percentage recovery of metals in C. macrostachyus leaves powder and its infusion samples were between $92 \%$ and $105 \%(100 \pm 10)$, which are within the acceptable range. The results are presented in Tables 3 and 4.

\section{Levels of major, trace and toxic metals}

The accuracy and precision of the method were tested by spiking the samples with a standard of known concentration of the analyte metals. The results indicated that the concentrations of elements determined by the present FAAS method are in agreement $(100 \pm 10 \%)$ within the acceptable range for all metals. Thus, in the present work, the concentration of the eleven metals, essential $(\mathrm{Ca}, \mathrm{Mg}, \mathrm{Mn}, \mathrm{Fe}, \mathrm{Cu}, \mathrm{Zn}, \mathrm{Co}, \mathrm{Cr}, \mathrm{Ni})$ and toxic $(\mathrm{Pb}, \mathrm{Cd})$ in the $\mathrm{C}$. 
macrostachyus leaves and their infusions were determined by FAAS. The results showed that the samples had variable composition of each analyte metals with wide concentration range. Among the identified eleven elements, all were found to be above the method detection limit except $\mathrm{Cd}$ not found in the samples from Dilla and Bonga sites in the C. macrostachyus leaves powder. On the other hand most metals were not detected in the infusion samples prepared for three and six hours. The results are given in Table 5 and 6.

Table 3. Recovery test results for C. macrostachyus leaves sample.

\begin{tabular}{|c|c|c|c|c|}
\hline Metal & $\begin{array}{c}\text { Conc. in } \\
\text { unspiked } \\
\text { sample }(\mu \mathrm{g} / \mathrm{g})^{\mathrm{a}}\end{array}$ & $\begin{array}{c}\text { Amount added } \\
(\mu \mathrm{g} / \mathrm{g})\end{array}$ & $\begin{array}{c}\text { Conc. in spiked } \\
\text { sample }(\mu \mathrm{g} / \mathrm{g})^{\mathrm{b}}\end{array}$ & ${\text { Recovery }(\%)^{\mathrm{c}}}^{\mathrm{c}}$ \\
\hline $\mathrm{Ca}$ & 12,040 & 1565 & $13,558 \pm 12$ & $97 \pm 7$ \\
\hline $\mathrm{Mg}$ & 4,961 & 992 & $5,884 \pm 8$ & $93 \pm 2$ \\
\hline $\mathrm{Fe}$ & 581 & 116 & $699 \pm 5$ & $102 \pm 3.5$ \\
\hline $\mathrm{Mn}$ & 283 & 56 & $338 \pm 3$ & $98 \pm 2.5$ \\
\hline $\mathrm{Zn}$ & 60.5 & 12 & $71.8 \pm 1.5$ & $94 \pm 1.4$ \\
\hline $\mathrm{Cu}$ & 18.6 & 10 & $28.2 \pm 0.8$ & $96 \pm 0.25$ \\
\hline $\mathrm{Co}$ & 2.18 & 1.20 & $3.32 \pm 4$ & $95 \pm 4.3$ \\
\hline $\mathrm{Cr}$ & 8.75 & 1.84 & $10.4 \pm 5$ & $92 \pm 8$ \\
\hline $\mathrm{Ni}$ & 2.62 & 1.68 & $4.27 \pm 0.3$ & $98 \pm 5.1$ \\
\hline $\mathrm{Cd}$ & 1.08 & 1.08 & $2.19 \pm 0.4$ & $103 \pm 6.2$ \\
\hline $\mathrm{Pb}$ & 2.19 & 1.75 & $3.84 \pm 5.1$ & $94 \pm 2.6$ \\
\hline
\end{tabular}

${ }^{a}$ Mean concentration in un-spiked samples analyzed in triplicate. ${ }^{b}$ Mean concentration \pm SD in spiked samples, spiked and analyzed in triplicate. ${ }^{c}$ Mean percentage recovery \pm SD of triplicate analyses.

Table 4. Recovery test results for C. macrostachyus leaves infusion sample.

\begin{tabular}{|c|c|c|c|c|}
\hline Metal & $\begin{array}{c}\text { Conc. in unspiked } \\
\text { sample }(\mu \mathrm{g} / \mathrm{g})^{\mathrm{a}}\end{array}$ & $\begin{array}{c}\text { Amount added } \\
(\mu \mathrm{g} / \mathrm{g})\end{array}$ & $\begin{array}{c}\text { Conc. in spiked } \\
\text { sample }(\mu \mathrm{g} / \mathrm{g})^{\mathrm{b}}\end{array}$ & ${\text { Recovery }(\%)^{\mathrm{c}}}^{\mathrm{c}}$ \\
\hline $\mathrm{Ca}$ & 1,824 & 365 & $2,182 \pm 4$ & $98 \pm 1.3$ \\
\hline $\mathrm{Mg}$ & 85.1 & 17.0 & $102 \pm 3$ & $97 \pm 3$ \\
\hline $\mathrm{Fe}$ & 6.50 & 1.95 & $8.33 \pm 2.8$ & $94 \pm 1.5$ \\
\hline $\mathrm{Mn}$ & 3.40 & 0.68 & $4.11 \pm 5$ & $105 \pm 5$ \\
\hline $\mathrm{Cu}$ & 9.48 & 5.69 & $15.1 \pm 7$ & $99 \pm 0.8$ \\
\hline $\mathrm{Zn}$ & 2.49 & 0.62 & $3.08 \pm 3.5$ & $95 \pm 4$ \\
\hline $\mathrm{Co}$ & 0.78 & 0.47 & $1.24 \pm 2$ & $98 \pm 2.5$ \\
\hline $\mathrm{Cr}$ & 2.41 & 1.45 & $3.80 \pm 1.5$ & $96 \pm 1.8$ \\
\hline $\mathrm{Ni}$ & 0.42 & 0.33 & $0.72 \pm 5$ & $93 \pm 2$ \\
\hline $\mathrm{Cd}$ & 0.210 & 0.21 & $0.41 \pm 4.5$ & $97 \pm 3.5$ \\
\hline $\mathrm{Pb}$ & 0.41 & 0.32 & $0.71 \pm 3.5$ & $95 \pm 2.4$ \\
\hline
\end{tabular}

${ }^{a}$ Mean concentration in un-spiked samples analyzed in triplicate. ${ }^{b}$ Mean concentration \pm SD in spiked samples, spiked and analyzed in triplicate. ${ }^{c}$ Mean percentage recovery \pm SD of triplicate analyses.

\section{Distribution of metals in different C. macrostachyus samples}

Plants accumulate minerals essential for their growth from the environment and can also accumulate metals such as $\mathrm{Cd}, \mathrm{Co}, \mathrm{Ag}$, and $\mathrm{Na}$, which have no known direct benefit to the plant [31]. Therefore, the essential and non-essential metals in C. macrostachyus leaves and their infusion may be affected by different factors. Physical and chemical properties of the soil, taking medicinal samples from the farm areas (where application of natural and artificial 
fertilizers taking place), increasing industrialization and associated pollution of the biosphere, storage and processing of $C$. macrostachyus samples, climatic condition of the region and other factors are the main contributors for the mineral contents of $C$. macrostachyus leaves and their infusion.

\section{Concentration of metals in C. macrostachyus leaves powder}

Table 5 shows the mean concentrations of various metals, in the same C. macrostachyus species plant in different part of the country. From the study, it was revealed that all the metals were accumulated to greater or lesser extents by plant leave studied.

Table 5. Mean concentration $(\mathrm{X} \pm \mathrm{SD}, \mathrm{n}=9, \mu \mathrm{g} / \mathrm{g}$ dry weight $)$ of essential and toxic metals in $C$. macrostachyus leaves samples.

\begin{tabular}{|c|c|c|c|c|}
\hline \multirow{2}{*}{ Metal } & \multicolumn{4}{|c|}{ Concentration of metal $(\mu \mathrm{g} / \mathrm{g})$ dry weight basis } \\
\cline { 2 - 5 } & Akaki leaves & Abomsa leaves & Bonga leaves & Dilla leaves \\
\hline $\mathrm{Ca}$ & $12,040 \pm 840$ & $7,976 \pm 370$ & $5,823 \pm 81$ & $8,202 \pm 430$ \\
\hline $\mathrm{Mg}$ & $4,961 \pm 32$ & $2,361 \pm 54$ & $2,384 \pm 29$ & $1,971 \pm 20$ \\
\hline $\mathrm{Fe}$ & $581 \pm 40$ & $329 \pm 7.1$ & $269 \pm 6$ & $192 \pm 4$ \\
\hline $\mathrm{Mn}$ & $283 \pm 5$ & $157 \pm 7.5$ & $1,770 \pm 70$ & $421 \pm 9$ \\
\hline $\mathrm{Zn}$ & $60.5 \pm 2.3$ & $34.5 \pm 2.6$ & $33.6 \pm 1.1$ & $19.7 \pm 0.6$ \\
\hline $\mathrm{Cu}$ & $18.6 \pm 0.7$ & $8.20 \pm 0.70$ & $7.75 \pm 0.59$ & $6.31 \pm 0.48$ \\
\hline $\mathrm{Co}$ & $2.18 \pm 0.07$ & $3.45 \pm 0.26$ & $3.36 \pm 0.11$ & $1.97 \pm 0.06$ \\
\hline $\mathrm{Cr}$ & $8.75 \pm 0.66$ & $8.15 \pm 0.22$ & $2.13 \pm 0.09$ & $6.02 \pm 0.26$ \\
\hline $\mathrm{Ni}$ & $2.62 \pm 0.11$ & $2.15 \pm 0.16$ & $3.16 \pm 0.26$ & $3.8 \pm 0.10$ \\
\hline $\mathrm{Cd}$ & $1.08 \pm 0.09$ & $0.75 \pm 0.02$ & $\mathrm{ND}$ & $\mathrm{ND}$ \\
\hline $\mathrm{Pb}$ & $2.19 \pm 0.09$ & $1.15 \pm 0.02$ & $2.07 \pm 0.12$ & $1.05 \pm 0.1$ \\
\hline
\end{tabular}

From Table 5, it is clear that $\mathrm{Ca}$ was present in all the samples collected from four different regions with concentration ranging from 5,823 to $12,040 \mu \mathrm{g} / \mathrm{g}$. Among all these regions the highest concentration of $\mathrm{Ca}$ was found in Akaki C. macrostachyus leave powder and the lowest in Bonga C. macrostachyus leave powder. The concentration of $\mathrm{Ca}$ found in Abomsa and Dilla C. macrostachyus leaves powder were 7,976 and 8,202 $\mu \mathrm{g} / \mathrm{g}$. The higher concentrations of $\mathrm{Ca}$ are very significant because $\mathrm{Ca}$ is known to enhance the qualities of bones and teeth and also of neuromuscular systemic and cardiac functions.

The Mg concentration varied from 1,971 to 4,961 $\mu \mathrm{g} / \mathrm{g}$. Dilla C. macrostachyus leaves had the lowest $\mathrm{Mg}$ concentration $(1,971 \mu \mathrm{g} / \mathrm{g})$ while Akaki C. macrostachyus leaves had the highest $(4,961 \mu \mathrm{g} / \mathrm{g})$. The Mg concentration of Abomsa and Bonga C. macrostachyus leaves were 2,361 and $2,384 \mu \mathrm{g} / \mathrm{g}$, respectively. Like $\mathrm{Ca}, \mathrm{Mg}$ is critical to many cell functions.

The abundance of $\mathrm{Ca}$ and $\mathrm{Mg}$ in the C. macrostachyus leaves is also in agreement with the previous studies on other plants, which indicated that these two elements were the most abundant elements in many medicinal plants and tea leaves [32, 33].

The Fe concentration varied in the range from $192 \mu \mathrm{g} / \mathrm{g}$ in Dilla C. macrostachyus leaves to $581 \mu \mathrm{g} / \mathrm{g}$ in Akaki C. macrostachyus leaves. The concentration of Fe found in Abomsa and Bonga C. macrostachyus leaves powder were 329 and $269 \mu \mathrm{g} / \mathrm{g}$, respectively. The plant in all the four regions accumulates $\mathrm{Fe}$ above the limits proposed by FAO/WHO in edible plants (20 $\mu \mathrm{g} / \mathrm{g}$ ). However, for medicinal plants the WHO limits not yet been established for Fe. Sheded et al. [34] reported that the range of Fe in their study was between 261 to $1,239 \mu \mathrm{g} / \mathrm{g}$ in selective medicinal plants of Egypt, thus the present result is in good agreement with this range.

Coming to the case of $\mathrm{Mn}$, an appreciable amount of Mn was present in all the areas of the study, its concentration is maximum in Bonga C. macrostachyus leaves 1,770 $\mu \mathrm{g} / \mathrm{g}$ and 
minimum in Abomsa C. macrostachyus leaves powder $(157 \mu \mathrm{g} / \mathrm{g})$. The concentration of Mn found in Akaki and Dilla C. macrostachyus leaves powder were 283 and $421 \mu \mathrm{g} / \mathrm{g}$, respectively. Similar to Fe, the plants in all the four regions accumulated Mn above the limits proposed by FAO/WHO in edible plants $(2 \mu \mathrm{g} / \mathrm{g})$. However, for medicinal plants the WHO limits not yet been established for $\mathrm{Mn}$, the range of $\mathrm{Mn}$ in five medicinal plants studied in Spain had concentration ranging from 46 to $2134 \mathrm{mg} / \mathrm{kg}$ [35].

From Table 5, it is clear that $\mathrm{Zn}$ was present in all the medicinal plants with concentration ranging from 19.7 to $60.5 \mu \mathrm{g} / \mathrm{g}$. Among all these study areas the highest concentration of $\mathrm{Zn}$ is found in Akaki C. macrostachyus leaves powder $(60.5 \mu \mathrm{g} / \mathrm{g})$ and the lowest concentration is found in Dilla C. macrostachyus leaves powder $(19.7 \mu \mathrm{g} / \mathrm{g})$. The concentration of $\mathrm{Zn}$ found in Abomsa and Bonga C. macrostachyus leaves powder are comparable, 34.5 and $33.6 \mu \mathrm{g} / \mathrm{g}$, respectively. The permissible zinc limit set by FAO/WHO in edible plants was $27.4 \mu \mathrm{g} / \mathrm{g}$. After comparison, metal limit in the studied medicinal plant with those proposed by FAO/WHO it is found that only Dilla C. macrostachyus leave is within this limit while all others study area accumulate $\mathrm{Zn}$ above this limit. However, for medicinal plants the WHO limits not yet been established for $\mathrm{Zn}$. According to Bowen and Allaway, the range of $\mathrm{Zn}$ in agricultural products was between 15 to $200 \mu \mathrm{g} / \mathrm{g}$ [36].

Copper was detected in all samples with varying concentrations. Leaves powder of $C$. macrostachyus from Akaki contain the highest amount $(18.6 \mu \mathrm{g} / \mathrm{g})$ of $\mathrm{Cu}$ while least concentration was exhibited in the leaves powder of C. macrostachyus from Dilla $(6.31 \mu \mathrm{g} / \mathrm{g})$. Abomsa and Bonga C. macrostachyus leaves powder contains comparable amount of $\mathrm{Cu}, 8.20$ and $7.75 \mu \mathrm{g} / \mathrm{g}$, respectively. Although the results are not in the permissible limit of $\mathrm{Cu}$ set by $\mathrm{FAO} / \mathrm{WHO}$ in edible plants $3.0 \mu \mathrm{g} / \mathrm{g}$, the results obtained from our medicinal plant are in the permissible limit of $\mathrm{Cu}$ set by China and Singapore in medicinal plants, which were 20 and 150 $\mu \mathrm{g} / \mathrm{g}$, respectively. Reddy and Reddy [37] also reported that the range of $\mathrm{Cu}$ contents in the 50 medicinally important leafy material growing in India were 17.6 to $57.3 \mu \mathrm{g} / \mathrm{g}$.

The Co content was observed to be the highest, $3.45 \mu \mathrm{g} / \mathrm{g}$ in Abomsa C. macrostachyus leaves powder and relatively comparable in Bonga C. macrostachyus leaves powder $(3.36 \mu \mathrm{g} / \mathrm{g})$. The concentration of Co found in Akaki and Dilla C. macrostachyus leaves powder are 2.18 $\mu \mathrm{g} / \mathrm{g}$ and $1.97 \mu \mathrm{g} / \mathrm{g}$, respectively. There are no established criteria for Co in medicinal plants. Basgel and Erdemoglu [38] determined Co concentration ranged between 0.14 to $0.48 \mu \mathrm{g} / \mathrm{g}$ in seven herbs in Turkey.

Another essential element, $\mathrm{Cr}$, acts as a co-factor in the insulin synthesis and in the cholesterol and blood triglycerides control. The $\mathrm{Cr}$ content was observed to be the highest, 8.75 $\mu \mathrm{g} / \mathrm{g}$ in Akaki C. macrostachyus leaves powder and relatively comparable in Abomsa $C$. macrostachyus leaves powder $(8.15 \mu \mathrm{g} / \mathrm{g})$. The concentration of $\mathrm{Cr}$ found in Bonga and Dilla $C$. macrostachyus leaves powder are 2.13 and $6.2 \mu \mathrm{g} / \mathrm{g}$, respectively.

Abomsa C. macrostachyus leave accumulated lowest Ni that is, $2.15 \mu \mathrm{g} / \mathrm{g}$ and Dilla $C$. macrostachyus leave accumulate maximum that is $3.80 \mu \mathrm{g} / \mathrm{g}$. The concentration of $\mathrm{Ni}$ found in Bonga and Akaki C. macrostachyus leaves powder were 3.16 and $2.62 \mu \mathrm{g} / \mathrm{g}$, respectively. The permissible limit set by FAO/WHO in edible plants was $1.63 \mu \mathrm{g} / \mathrm{g}$. However, for medicinal plants the WHO limits not yet been established for Ni. Ni toxicity in human is not a very common occurrence because its absorption by the body is very low [39].

It is well known that $\mathrm{Pb}$ and $\mathrm{Cd}$ are toxic metals because of their effect in disordering the biological activity once taken into the body. In this study, $\mathrm{Cd}$ was not detected in Dilla and Bonga C. macrostachyus leaves powder. Elevated $\mathrm{Cd}$ concentrations were determined in Abomsa C. macrostachyus leave $0.75 \mu \mathrm{g} / \mathrm{g}$ next to Akaki C. macrostachyus leave $1.08 \mu \mathrm{g} / \mathrm{g}$. The permissible limit for $\mathrm{Cd}$ set by $\mathrm{FAO} / \mathrm{WHO}$ in edible plants was $0.2 \mu \mathrm{g} / \mathrm{g}$. However, for medicinal plants the permissible limit for Cd set by WHO, China and Thailand was $0.3 \mu \mathrm{g} / \mathrm{g}$. The relatively high concentrations of $\mathrm{Cd}$ found in the C. macrostachyus samples are certainly 
due to industrial pollution as well as the addition of some fertilizers and herbicides on the farm and farm sides.

The content of $\mathrm{Pb}$ in the C. macrostachyus leaves analyzed varied between 1.05 and 2.19 $\mu \mathrm{g} / \mathrm{g}$ which is lower than the permissible limit for medicinal plant set by China, Malaysia, Thailand and WHO $\left(10 \mathrm{mg} \mathrm{kg}^{-1}\right)$. The maximum concentrations of $\mathrm{Pb}$ were determined in Bonga C. macrostachyus leaves $(2.07 \mu \mathrm{g} / \mathrm{g})$ next to Akaki C. macrostachyus leaves $(2.19 \mu \mathrm{g} / \mathrm{g})$. The concentration of $\mathrm{Pb}$ found in Abomsa and Dilla C. macrostachyus leaves were 1.15 and $1.05 \mu \mathrm{g} / \mathrm{g}$, respectively.

Most of the studied sites showed more or less comparable pattern in mineral accumulation in the plant. Thus the following pattern in decreasing order was notice: $\mathrm{Ca}>\mathrm{Mg}>\mathrm{Fe}>\mathrm{Mn}>\mathrm{Zn}>$ $\mathrm{Cu}>\mathrm{Cr}>\mathrm{Ni}>\mathrm{Pb}>\mathrm{Co}>\mathrm{Cd}$.

\section{Concentration of metals in a 3, 6, 12 and 24 hours infusion}

As shown in Table 6, the trend of average concentration of metals in the $24 \mathrm{~h}$ infusion was $\mathrm{Ca}>$ $\mathrm{Mg}>\mathrm{Zn}>\mathrm{Mn}>\mathrm{Fe}>\mathrm{Cu}>\mathrm{Cr}>\mathrm{Ni}>\mathrm{Co}>\mathrm{Pb}>\mathrm{Cd}$. Similarly, the pattern of the average concentration of metals in the $12 \mathrm{~h}$ infusion was $\mathrm{Ca}>\mathrm{Mg}>\mathrm{Fe}>\mathrm{Zn}>\mathrm{Mn}>\mathrm{Cu}>\mathrm{Cr}>\mathrm{Ni}>\mathrm{Co}$ $>\mathrm{Pb}>\mathrm{Cd}$. Ca was appreciably extracted with the amount, $1,776 \mu \mathrm{g} / \mathrm{g}$ followed by $\mathrm{Mg}, 80.9$ $\mu \mathrm{g} / \mathrm{g}$ in the 24 hour infusion sample. Among the trace metals, Zn $(7.88 \mu \mathrm{g} / \mathrm{g})$ was leached in larger amount followed by $\mathrm{Mn}, \mathrm{Fe}$ and $\mathrm{Cu}$ with concentrations $(3.40,3.20$ and $2.31 \mu \mathrm{g} / \mathrm{g}$ ), respectively. Other trace metals, $\mathrm{Cr}, \mathrm{Ni}$ and $\mathrm{Co}$ were also extracted in lower concentration in the $24 \mathrm{~h}$ and $12 \mathrm{~h}$ of extraction time. The lower concentrations of these metals are most likely due to the small intake of these metals by the plant and also due to their low extraction efficiency in the water as these transition metals are known to form stable complexes with organic molecules present in the plant leaves. The toxic heavy metals $\mathrm{Cd}$ and $\mathrm{Pb}$ were also detected in the 24 hour infusion sample. The amount of $\mathrm{Cd}$ and $\mathrm{Pb}$ detected in this infusion sample were $0.098 \mu \mathrm{g} / \mathrm{g}$ and $0.185 \mu \mathrm{g} / \mathrm{g}$, respectively.

Table 6. Mean concentration ( $\mathrm{X} \pm \mathrm{SD}, \mathrm{n}=9, \mu \mathrm{g} / \mathrm{g}$ wet weight) of essential and toxic metals in infusion samples.

\begin{tabular}{|c|c|c|c|c|}
\hline \multirow{2}{*}{ Metal } & \multicolumn{3}{|c|}{ Concentration of metal $(\mu \mathrm{g} / \mathrm{g})$ wet weight basis in infusions extracted for } \\
\cline { 2 - 5 } & 3 hour & 6 hour & 12 hour & 24 hour \\
\hline $\mathrm{Ca}$ & $716 \pm 19$ & $904 \pm 29$ & $1,091 \pm 40$ & $1,776 \pm 41$ \\
\hline $\mathrm{Mg}$ & $16.7 \pm 0.9$ & $17.9 \pm 1.2$ & $40.5 \pm 0.5$ & $80.9 \pm 2.2$ \\
\hline $\mathrm{Fe}$ & $1.39 \pm 0.02$ & $1.53 \pm 0.02$ & $3.34 \pm 0.04$ & $3.20 \pm 0.24$ \\
\hline $\mathrm{Mn}$ & $2.17 \pm 0.03$ & $2.65 \pm 0.20$ & $2.99 \pm 0.07$ & $3.40 \pm 0.04$ \\
\hline $\mathrm{Zn}$ & $0.674 \pm 0.1$ & $1.68 \pm 0.02$ & $3.02 \pm 0.10$ & $7.88 \pm 0.39$ \\
\hline $\mathrm{Cu}$ & $1.94 \pm 0.07$ & $2.10 \pm 0.14$ & $2.23 \pm 0.004$ & $2.31 \pm 0.11$ \\
\hline $\mathrm{Co}$ & $0.157 \pm 0.01$ & $0.165 \pm 0.01$ & $0.184 \pm 0.013$ & $0.224 \pm 0.008$ \\
\hline $\mathrm{Cr}$ & $0.144 \pm 0.02$ & $0.454 \pm 0.012$ & $0.539 \pm 0.18$ & $1.23 \pm 0.09$ \\
\hline $\mathrm{Ni}$ & $0.203 \pm 0.004$ & $0.237 \pm 0.008$ & $0.238 \pm 0.01$ & $0.267 \pm 0.013$ \\
\hline $\mathrm{Cd}$ & $\mathrm{ND}$ & $\mathrm{ND}$ & $0.050 \pm 0.003$ & $0.098 \pm 0.007$ \\
\hline $\mathrm{Pb}$ & $0.0148 \pm 0.001$ & $0.082 \pm 0.007$ & $0.136 \pm 0.004$ & $0.185 \pm 0.004$ \\
\hline
\end{tabular}

The percentage of leaching of the metals was also calculated and results are shown in Figure 1. As can be seen from the figure, each of the metal was extracted from the $C$. macrostachyus leaves to the water at different rate. For all the metals studied, maximum percentage extraction was observed at $24 \mathrm{~h}$ of infusion time followed by the subsequent lower extraction times. This highest leaching rate is appreciable for the essential metals. Whereas, for some of the trace metals and toxic elements, rate of extraction was more pronounced with infusion time. For instance, $\mathrm{Cd}$ was not detected in the infusion time of 3 and $6 \mathrm{~h}$, while $2.80 \%$ and $15.5 \%$ was 
leached for $\mathrm{Pb}$ for the extraction time of 3 and $6 \mathrm{~h}$, respectively. The extraction efficiencies for these two metals proportionally increased with time of infusion. Thus we recommend to the traditional practitioners to infuse their samples at lower period of time as possible so as to minimize the risk of these two heavy metal toxicity.

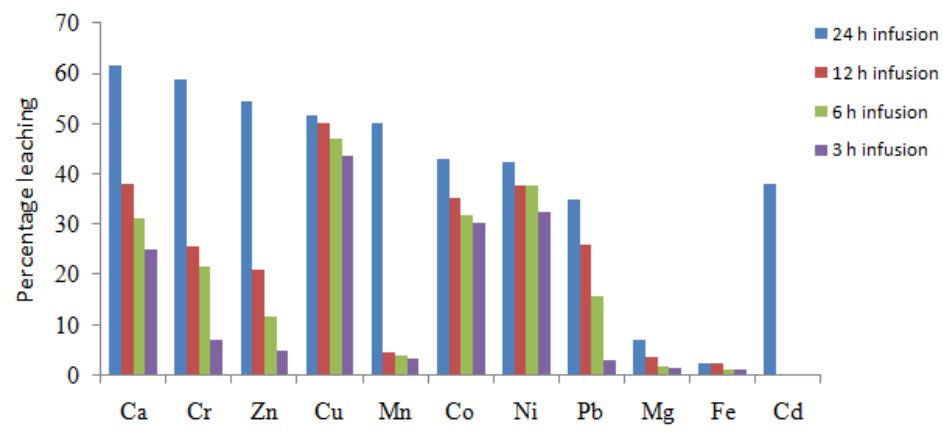

Figure 1. Percentage leaching of metals in $24 \mathrm{~h}, 12 \mathrm{~h}, 6 \mathrm{~h}$ and $3 \mathrm{~h}$ C. macrostachyus leaves infusions.

Table 7. Metal concentrations ( $\mu \mathrm{g} / \mathrm{g})$ of C. macrostachyus leaves powder in wet weight basis and range of concentration of metals $(\mu \mathrm{g} / \mathrm{g})$ in different infusion time.

\begin{tabular}{|c|c|c|}
\hline Metal & $\begin{array}{c}\text { C. macrostachyus leaves powder } \\
\text { in }(\mu \mathrm{g} / \mathrm{g}) \text { fresh weight basis }{ }^{\mathrm{a}}\end{array}$ & $\begin{array}{c}\text { C. macrostachyus leaves infusion } \\
\text { in }(\mu \mathrm{g} / \mathrm{g}) \text { fresh weight basis }\end{array}$ \\
\hline $\mathrm{Ca}$ & 2,887 & $716-1,776$ \\
\hline $\mathrm{Mg}$ & 1,190 & $16.7-80.9$ \\
\hline $\mathrm{Fe}$ & 139 & $1.39-3.34$ \\
\hline $\mathrm{Mn}$ & 67.9 & $2.17-3.40$ \\
\hline $\mathrm{Zn}$ & 14.5 & $0.674-7.88$ \\
\hline $\mathrm{Cu}$ & 4.46 & $1.94-2.31$ \\
\hline $\mathrm{Co}$ & 0.52 & $0.157-0.224$ \\
\hline $\mathrm{Cr}$ & 2.10 & $0.144-1.23$ \\
\hline $\mathrm{Ni}$ & 0.63 & $0.203-0.267$ \\
\hline $\mathrm{Cd}$ & 0.26 & $0.05-0.098$ \\
\hline $\mathrm{Pb}$ & 0.53 & $0.0148-0.185$ \\
\hline
\end{tabular}

${ }^{\mathrm{a} C}$ Conversion were made for Akaki leaves sample using a conversion facto of 4.17. ${ }^{\mathrm{b}}$ Infusion time between 3 and 24

Generally, for most of the metals investigated their concentration in the extract increase with prolonged period of infusion time, i.e. highest concentration were noticed in the $24 \mathrm{~h}$ followed by 12, 6 and $3 \mathrm{~h}$. This might be due to the fact that the solvent might get the opportunity to penetrate the matrix and solvate the ions and hence easily leached in to the filtrate. Furthermore, wide variations in extent of extraction were also noticed among metals (Table 6, Figure 1). Range of metals extracted with time for Akaki leaves sample is given in Table 7.

\section{Comparison of metals in the C. macrostachyus leaves powder samples}

The concentrations of the elements in the analyzed samples were quite varied. The order of the metal concentration from Akaki C. macrostachyus leaves powder and Abomsa $C$. macrostachyus leaves powder is almost similar except that the Akaki C. macrostachyus leaves powder with lower mean concentration of $\mathrm{Co}$ than $\mathrm{Ni}$ and $\mathrm{Pb}$. The trend in metal concentration for that of the Bonga and Dilla C. macrostachyus leaves powder were the same for $\mathrm{Ca}, \mathrm{Mg}$ and 
$\mathrm{Fe}$ concentration. However, the concentration of $\mathrm{Fe}$ was greater than that of $\mathrm{Zn}$ and the concentration $\mathrm{Cr}$ were lower than the concentration of Ni which were not true for Dilla $C$. macrostachyus leave powder. Ca was found at highest concentration than other metals in all the four sample sites, with the mean concentration ranging from $5,823 \mu \mathrm{g} / \mathrm{g}$ (Bonga $C$. macrostachyus leaves powder) to $12,040 \mu \mathrm{g} / \mathrm{g}$ (Akaki C. macrostachyus leaves powder). Similarly, Mg was the next highest than other metals all the sites. The concentration of Fe was the third next to Mg but Mn was the next highest than the other metals for Bonga $(1,770 \mu \mathrm{g} / \mathrm{g})$ and Dilla $(421 \mu \mathrm{g} / \mathrm{g})$ sites.

$\mathrm{Zn}$ was found to be the third highest amount out of the microelements analyzed with mean concentration ranging from $19.7 \mu \mathrm{g} / \mathrm{g}$ (Dilla C. macrostachyus leaves powder) to $60.5 \mu \mathrm{g} / \mathrm{g}$ (Akaki C. macrostachyus leaves powder) followed by $\mathrm{Cu}$ with mean concentration range 6.31 $\mu \mathrm{g} / \mathrm{g}$ (Dilla C. macrostachyus leaves powder) to $18.6 \mu \mathrm{g} / \mathrm{g}$ (Akaki C. macrostachyus leaves powder). The lowest concentration observed for all the four sites was that of $\mathrm{Cd}$, ranging from $0.75 \mu \mathrm{g} / \mathrm{g}$ (Abomsa C. macrostachyus leaves powder) to $1.08 \mu \mathrm{g} / \mathrm{g}$ (Akaki C. macrostachyus leaves powder). Overall, the concentrations of each metal in the four sites are comparable.

Generally, Akaki C. macrostachyus leaves powder contained higher concentration of all the metals than other C. macrostachyus leaves samples but its $\mathrm{Mn}$, Co and Ni contents were least. Abomsa C. macrostachyus leaves powder contained higher concentration of $\mathrm{Fe}, \mathrm{Zn}, \mathrm{Cu}, \mathrm{Cr}$ and Cd next to Akaki C. macrostachyus leaves powder while Dilla C. macrostachyus leaves powder contained least amount of $\mathrm{Mg}, \mathrm{Fe}, \mathrm{Zn}, \mathrm{Cu}, \mathrm{Co}, \mathrm{Cd}$ and $\mathrm{Pb}$ as can been seen from Table 5. This trend of concentration is also similar for the other C. macrostachyus leaves samples.

Comparison of the metal content in C. macrostachyus leaves and infusion samples with other medicinal plants

Results of the present study were compared with reported data on other medicinal plants from other parts of the world. Results of the comparison are given in Table 8. Looking at the table diversified concentration of metals in different species was noticed. However, the range of metals in the present study falls within the range of the reported data. For some of the species, higher concentrations for some of the metals were noticed compared to the present study while lower concentrations were found for some of the others. These variations might be attributed due to variation in species and family of the plants analyzed. Furthermore, environmental and geographical variations might have significant effect on the nutrients accumulation in the plants.

The metals concentrations in the infusion samples were also compared with other medicinal plants leaves from other parts of the world (Table 9). Looking at the table, extent of extractions from the leaves in to the infusions was comparable with the present study for most of the metals investigated. Higher concentrations in the infusion were noticed for those metals in higher concentration in the leaves for almost all of the plants compared. While small concentrations were observed for those whose concentrations were smaller in the leaves. Generally speaking, the range of mineral concentrations in the infusion of the present study was within the range of the plants compared. 
Table 8. Comparison of metal concentration $(\mu \mathrm{g} / \mathrm{g})$ in C. macrostachyus leaves with other medicinal plant leaves.

A

\begin{tabular}{|l|c|c|c|c|c|c|c|}
\hline \multirow{2}{*}{ Medicinal Plant } & \multirow{2}{*}{ Origin } & \multicolumn{2}{|l|}{ Concentration $(\mu \mathrm{g} / \mathrm{g})$ of metals in medicinal plants } & Ref. \\
\cline { 3 - 8 } & & $\mathrm{Ca}$ & $\mathrm{Mg}$ & $\mathrm{Mn}$ & $\mathrm{Fe}$ & $\mathrm{Zn}$ & \\
\hline Taraxacum officinale Weber & Spain & 29247 & 4461 & 101 & 853 & 68 & {$[36]$} \\
\hline Eucalyptus globulus Labill & Spain & 18621 & 1616 & 2134 & 89 & 23 & {$[36]$} \\
\hline Plantago major L. & Bulgaria & 48022 & 6405 & 46 & 373 & 56 & {$[36]$} \\
\hline Mentha piperita L. & Bulgaria & 21131 & 5483 & 116 & 376 & 45 & {$[36]$} \\
\hline Matricaria chamomilla L. & Egypt & 926 & 2642 & 76 & 701 & 49 & {$[36]$} \\
\hline Calotropis procera Ait. & Nigeria & 18900 & - & 232 & 1872 & 71.7 & {$[36]$} \\
\hline Acalypha wilkensiana & Nigeria & 28400 & - & 44.4 & 760 & 75.3 & {$[40]$} \\
\hline Euphorbia hirta Linn. & Nigeria & 8120 & - & 52 & 536 & 191 & {$[40]$} \\
\hline Pelargonium graveolens L. & Egypt & - & - & 26.4 & 516 & 12.1 & {$[39]$} \\
\hline Marjorana hortensis L. & Egypt & - & - & 28 & 671 & 10.6 & {$[39]$} \\
\hline Gynostemma pentaphyllum & Thailand & $5583-34070$ & $1756-7739$ & $43.4-259$ & $126-2321$ & $25.4-61.9$ & {$[33]$} \\
\hline Camellia sinensis & Thailand & $1384-6550$ & $784-2549$ & $229-1512$ & $20.9-318$ & $10.1-55.4$ & {$[33]$} \\
\hline Morus alba & Thailand & $15286-25182$ & $3078-5188$ & $75.3-353$ & $89.5-408$ & $19.2-34.4$ & {$[33]$} \\
\hline Croton macrostachyus & Ethiopia & $5,823-12,040$ & $1971-4961$ & $157-1,770$ & $192-581$ & $19.7-60.5$ & This study \\
\hline
\end{tabular}

B

\begin{tabular}{|l|c|c|c|c|c|c|c|}
\hline \multirow{2}{*}{ Medicinal Plant } & \multirow{2}{*}{ Origin } & \multicolumn{3}{|c|}{ Concentration $(\mu \mathrm{g} / \mathrm{g})$ of metals in medicinal plants } & \multirow{2}{*}{ Ref. } \\
\cline { 3 - 7 } & & $\mathrm{Cu}$ & $\mathrm{Ni}$ & $\mathrm{Cr}$ & $\mathrm{Cd}$ & $\mathrm{Pb}$ & \\
\hline Taraxacum officinale Weber & Spain & 27 & - & - & - & 7 & {$[36]$} \\
\hline Eucalyptus globulus Labill & Spain & 10 & - & - & - & 6 & {$[36]$} \\
\hline Plantago major L. & Bulgaria & 13 & - & - & - & 6 & {$[36]$} \\
\hline Mentha piperita L. & Bulgaria & 19 & - & - & - & 8 & {$[36]$} \\
\hline Matricaria chamomilla L. & Egypt & 20 & - & - & - & 3 & {$[36]$} \\
\hline Calotropis procera Ait. & Nigeria & 138 & 235 & 199 & - & - & {$[40]$} \\
\hline Acalypha wilkensiana & Nigeria & 146 & 204 & 34.6 & - & - & {$[40]$} \\
\hline Euphorbia hirta Linn. & Nigeria & 235 & 241 & - & - & - & {$[40]$} \\
\hline Marjorana hortensis L. & Egypt & 3.95 & 25.3 & 2.15 & 2.05 & 14.4 & {$[39]$} \\
\hline Gynostemma pentaphyllum & Thailand & $5.14-15.5$ & $0.53-6.60$ & $0.43-12.4$ & $0.021-4.77$ & $0.36-64.4$ & {$[33]$} \\
\hline Camellia sinensis & Thailand & $3.08-22.4$ & $2.28-9.19$ & $0.21-10.5$ & $0.002-0.10$ & $0.060-53.9$ & {$[33]$} \\
\hline Morus alba & Thailand & $5.72-11.1$ & $0.37-2.17$ & $0.25-1.42$ & $0.001-0.022$ & $0.12-1.18$ & {$[33]$} \\
\hline Croton macrostachyus & Ethiopia & $6.31-18.6$ & $2.15-3.80$ & $2.13-8.75$ & $0.75-1.08$ & $1.05-2.19$ & This study \\
\hline
\end{tabular}

Table 9. Comparison of metal contents of C. macrostachyus leaves infusion with other medicinal plant leaves infusion.

\begin{tabular}{|l|c|c|c|c|c|}
\hline \multirow{2}{*}{ Medicinal plant } & \multicolumn{6}{|c|}{ Concentration $(\mu \mathrm{g} / \mathrm{g})$ of metals in infusion of medicinal plants } & \multirow{2}{*}{ Ref. } \\
\cline { 2 - 5 } & $\mathrm{Cu}$ & $\mathrm{Cr}$ & $\mathrm{Cd}$ & $\mathrm{Pb}$ & \\
\hline Taraxacum officinale Weber & 0.18 & - & - & 0.011 & {$[36]$} \\
\hline Eucalyptus globulus Labill & 0.068 & - & - & 0.049 & {$[36]$} \\
\hline Plantago major L. & 0.11 & - & - & 0.007 & {$[36]$} \\
\hline Mentha piperita L. & 0.11 & - & - & 0.025 & {$[36]$} \\
\hline Matricaria chamomilla L. & 0.21 & - & - & 0.036 & {$[36]$} \\
\hline Gynostemma pentaphyllum & $1.62-7.99$ & $0.00-1.41$ & $0.103-2.31$ & $0.113-8.02$ & {$[33]$} \\
\hline Camellia sinensis & $1.20-8.43$ & $0.00-0.69$ & $0.004-0.024$ & $0.0004-3.16$ & {$[33]$} \\
\hline Morus alba & $1.48-7.39$ & $0.00-0.40$ & $0.00-0.028$ & $0.0075-0.15$ & {$[33]$} \\
\hline Croton macrostachyus & $1.94-2.31$ & $0.14-1.2$ & $0.05-0.098$ & $0.015-0.18$ & This study \\
\hline
\end{tabular}


Statistical analysis

Analysis of variance (ANOVA) [41] was used to evaluate the difference in concentration of metals among the sampling sites were significant or not. Except between Abomsa/Dilla $C$. macrostachyus leaves powder samples, there was a significant difference $(p<0.05)$ in mean concentrations of $\mathrm{Ca}$ at $95 \%$ confidence interval between all the four samples of $C$. macrostachyus leave powder when pair wise comparison was made. For $\mathrm{Mg}, \mathrm{Fe}, \mathrm{Mn}$ and $\mathrm{Cd}$ significant difference $(\mathrm{p}<0.05)$ at $95 \%$ confidence interval was observed in their mean concentrations between all the four C. macrostachyus leave powder samples. The same was true for $\mathrm{Cu}$ and $\mathrm{Ni}$ except between Abomsa and Dilla whilst, no significant difference $(\mathrm{p}>0.05)$ in $\mathrm{Zn}$ and $\mathrm{Cu}$ concentration were observed for all the pair wise comparison except between Akaki and Abomsa C. macrostachyus leaf samples. Similarly, significant variation was in $\mathrm{Cr}$ and $\mathrm{Pb}$ concentration for all the pair wise comparison tests except between Akaki and Abomsa for $\mathrm{Cr}$ and Akaki and Bonga for $\mathrm{Pb}$.

Absence of significant difference in some mineral nutrient among samples from Akaki, Abomsa, Bonga and Dilla may indicate that these areas are under the same geographical location and share common climatic conditions. Similarly presence of significant difference in concentration for some minerals of C. macrostachyus leaves powder might aroused from the chemical composition of the leaves itself, the specific environmental conditions in which the plant was grown or the studied area might contains higher concentration of mineral nutrient in the soil [41].

\section{CONCLUSION}

Generally, C. macrostachyus (an Ethiopian traditional medicinal plant) accumulated appreciable amounts of major and trace metals in its leaves. $\mathrm{Ca}$ and $\mathrm{Mg}$ were the most abundant nutrients among the analyzed metals followed by, Fe, Mn and $\mathrm{Zn}$. All the metals enriched in the extract proportionally with extraction time but extent of leaching in the extract was significantly pronounced for the trace metals and the toxic metals $(\mathrm{Cd}$ and $\mathrm{Pb})$ for prolonged period of infusion. Thus, beside its medicinal value, C. macrostachyus leaves can be good source of mineral nutrients if further research is conducted to predict appropriate dose to be taken.

Statistical analysis revealed that significant variation in metal concentrations among the sampling sites was observed for some of the metals when pair wise test was made while insignificant variation were seen for the remaining metals. Existence of significant variation in the level of metals for the samples studied might be difference in environmental and/or climatic conditions. Difference in soil parameters might also have significant effect for the variation. Absence of significant variation might be due to the fact that similarity in the aforementioned parameters among the stated areas.

\section{ACKNOWLEDGMENTS}

The authors express their gratitude to the Department of Chemistry, Addis Ababa University, Ethiopia, for providing the laboratory facilities. Amare Aregahegn Dubale is thankful to Department of Chemistry, Dilla University, Ethiopia and NUFU project, Norway for sponsoring his study.

\section{REFERENCES}

1. Lanfranco, G. E. J. Biotechnol. 1999, 2, 1.

2. Demma, J.; Engidawork, E.; Hellman, B. J. Ethnopharmacol. 2009, 122, 136.

3. Kassaye, K.D.; Amberbir, A.; Getachew, B.; Mussema, Y. Ethiop. J. Health Develop. 2006, $20,127$. 
4. Baquar, S.R. The Role of Traditional Medicine in Rural Environment in Traditional Medicine in Africa, Issaq, S. (Ed.), East Africa Educational Publishers Ltd.: Nairobi; 1995; pp 141-142.

5. World Health Organization (WHO) General Guidelines for Methodologies on Research and Evaluation of Traditional Medicine, WHO: Geneva; 2001.

6. Derbie, A.; Chandravanshi, B.S. Biol. Trace Elem. Res. 2011, 141, 317.

7. Gebre, A.; Chandravanshi, B.S. Bull. Chem. Soc. Ethiop. 2012, 26, 329.

8. Abebe, D. The role of herbal remedies and the approaches towards their development in Proceedings of the Workshop on Development and Utilization of Herbal Remedies in Ethiopia, Nazareth, 1996; p 29.

9. Tadeg, H.; Mohammed, E.; Asres, K.; Gebre-Mariam, T. J. Ethnopharmacol. 2005, 100, 168.

10. Gidey M. An Ethanobotanical Study of Medicinal Plants Used by the Zay People in Ethiopia, CBM: Skriftserie 3, Uppsala; 2001, pp 81-89.

11. Desissa, D.; Binggeli, P. Uses and conservation status of medicinal plants used by the Shinasha people; 2000; Available at http://members.multimania.co.uk/ethiopianplants/shinasha.html. Accessed on 20 June 2012.

12. Breitenbach, F.V. The Indigenous Trees of Ethiopia, 2nd ed., Ethiopian Forestry Association: Addis Ababa; 1963; p 306.

13. Gidey, M.; Teklehaymanot, T.; Animut, A.; Mekonnen, Y. J. Ethnopharmacol. 2007, 110, 516.

14. Shukla, P.; Misra, S.P. An Introduction to Taxonomy of Angiosperms, Vikas Publishing House Pvt. Ltd.: Delhi; 1979; p 556.

15. Heywood, V.H. Flowering Plants of the World, Andromeda Oxford Ltd.: Oxford; 1993; p 335.

16. Tane, P.; Tatsimo, S.; Connolly, J.D. Tetrahedron Lett. 2004, 45, 6997.

17. Wakjira, K. Seed germination physiology and nursery establishment of Croton macrostachyus Hocht. Ex Del. M.Sc. Dissertation, Addis Ababa University, Addis Ababa, Ethiopia, 2007.

18. Yibralign, Z. Phytochemical investigation on the stem bark of Croton macrostachyus (Bisana). M.Sc. Dissertation, Addis Ababa University, Addis Ababa, Ethiopia, 2007.

19. Olajire, A.A.; Ayodele, E.T. Bull. Chem. Soc. Ethiop. 2003, 17, 11.

20. Cundeva, K.; Pavlovovska, G.; Stafilov, T. J. Braz. Chem. Soc. 2007, 18, 1207.

21. Yemane, M.; Chandravanshi, B.S.; Wondimu, T. Food Chem. 2008, 107, 1236.

22. Atlabachew, M.; Chandravanshi, B.S. J. Food Comp. Anal. 2008, 21, 545.

23. Atlabachew, M.; Chandravanshi, B.S.; Redi, M. Biol. Trace Elem. Res. 2010, 138, 316.

24. Weldegebriel, Y.; Chandravanshi, B.S.; Wondimu, T. Ecotoxicol. Environ. Saf. 2012, 77, 57.

25. Kitata, R.B.; Chandravanshi, B.S. Bull. Chem. Soc. Ethiop. 2012, 26, 27.

26. Aregahegn, A.; Chandravanshi, B.S.; Atlabachew, M. Afr. J. Food Agric. Nutr. Dev. 2013, 13,7870 .

27. Schumacher, M.; Bosque, M.A.; Domingo, J.L.; Corbella, J. Bull. Environ. Contam. Toxicol. 1991, 46, 320.

28. Somers, E. J. Food Sci. 1983, 39, 215.

29. Deckelbaum, R.J.; Palm, C.; Mutno, P.; Declerck, F. Food Nutr. Bull. 2006, 27, 335.

30. Liu, D.; Kottke, I. J. Biosci. 2004, 29, 329.

31. Raskin, I.; Kumar, P.B.A.; Dushenkov, S.; Salt, D.E. Curr. Opinion Biotechnol. 1994, 5, 285.

32. Piotr, K.; Zbigniew, F.; Anna, D.; Peter, O. Sci. Total Environ. 2007, 381, 99.

33. Al Moaruf, O.; Muibat, O.; Asiata, O.; Isiaka, A.; Nureni, O. Food Chem. 2004, 85, 67.

34. Sheded, G.M.; Pulford, I.D.; Hamed, I.A. J. Arid Environ. 2006, 66, 210. 
35. Sumontha, N.; Nuchanart, R.; Jutamaad, S. J. Agric. Food Chem. 2006, 54, 6939.

36. Rashed, M. J. Arid Environ. 1995, 29, 185.

37. Reddy, P.R.; Reddy, S.J. Chemosphere 1997, 34, 2193.

38. Basgel, S.; Erdemoğlu, S.B. Sci. Total Environ. 2006, 359, 82.

39. Lokhande, R.; Singare, P.; Andhele, M.; Acharya, R. Radiochem. 2009, 51, 321.

40. Obiajunwa, E.; Adeleke, A.; Olanrewaju, O. J. Radioanal. Nucl. Chem. 2002, 252, 473.

41. Miller, J.N.; Miller, J.C. Statistics and Chemometrics for Analytical Chemistry, 5th ed., Pearson, Harlow: England; 2005. 